\title{
Selective neuronal silencing using synthetic botulinum molecules alleviates chronic pain in mice
}

Article

Accepted Version

Maiarù, M., Leese, C., Certo, M., Echeverria-Altuna, I., Mangione, A. S., Arsenault, J., Davletov, B. and Hunt, S. P. (2018) Selective neuronal silencing using synthetic botulinum molecules alleviates chronic pain in mice. Science Translational Medicine, 10 (450). eaar7384. ISSN 1946-6234 doi: https://doi.org/10.1126/scitrans/med.aar7384 Available at https://centaur.reading.ac.uk/90875/

It is advisable to refer to the publisher's version if you intend to cite from the work. See Guidance on citing.

To link to this article DOI: http://dx.doi.org/10.1126/scitrans/med.aar7384

Publisher: American Association for the Advancement of Science

All outputs in CentAUR are protected by Intellectual Property Rights law, including copyright law. Copyright and IPR is retained by the creators or other copyright holders. Terms and conditions for use of this material are defined in the End User Agreement. 


\section{CentAUR}

Central Archive at the University of Reading

Reading's research outputs online 
Selective neuronal silencing using synthetic botulinum molecules alleviates chronic pain in mice.

${ }^{1}$ Maria Maiarù, ${ }^{2}$ Charlotte Leese, ${ }^{1}$ Michelangelo Certo, ${ }^{1}$ Irene Echeverria-Altuna, ${ }^{1}$ Antonina S. Mangione, ${ }^{3}$ Jason Arsenault, ${ }^{2}$ Bazbek Davletov*, ${ }^{1}$ Stephen P. Hunt*.

${ }^{1}$ Cell and Developmental Biology, Medawar Building (G13), Gower Street, London WC1E 6BT, UK.

${ }^{2}$ Department of Biomedical Science, University of Sheffield, South Yorkshire S10 2TN, UK.

${ }^{3}$ The Peter Gilgan Centre for Research and Learning, Neuroscience and Mental Health Department, The Hospital for Sick Children, Toronto, M5G 0A4, ON, Canada.

*Corresponding authors:

Bazbek Davletov: b.davletov@sheffield.ac.uk Stephen P. Hunt: hunt@ucl.ac.uk

Overline: Pain

One Sentence Summary: Silencing key neurons with botulinum toxin conjugates exerts long-lasting pain relief in mouse models of chronic pain. 


\begin{abstract}
Chronic pain is a widespread debilitating condition affecting millions of people worldwide. Although several pharmacological treatments for relieving chronic pain have been developed, they require frequent chronic administration and are often associated with severe adverse events, including overdose and addiction. Persistent increased sensitization of neuronal subpopulations of the peripheral and central nervous system has been recognized as a central mechanism mediating chronic pain, suggesting that inhibition of specific neuronal subpopulations might produce antinociceptive effects. We leveraged the neurotoxic properties of the botulinum toxin to specifically silence key pain processing neurons in the spinal cords of mice. We show that a single intrathecal injection of botulinum toxin conjugates produced long-lasting pain relief in mouse models of inflammatory and neuropathic pain without toxic side effects. Our results suggest that this strategy might be a safe and effective approach for relieving chronic pain while avoiding the adverse events associated with repeated chronic drug administration.
\end{abstract}

\title{
INTRODUCTION
}

Noxious stimuli of sufficient intensity to induce tissue damage leads to increased excitability of peripheral and central neuronal circuits that heightens pain experience and serves to protect damaged tissue from further trauma(1-4). In some cases ongoing disease or the failure of potentiated pain signaling networks to return to pre-injury levels leads to persistent or chronic pain conditions(5). Persistent pain is highly prevalent and extremely difficult to treat $(6,7)$ with widely prescribed drugs such as opioids having significant unwanted side effects(7-9). While research into developing new analgesic drug therapies has been intense, translating knowledge 
from preclinical observations in animal models to new therapies in the clinic has been challenging(6). Research into the control of chronic pain states has however identified pathways connecting the spinal cord and brain that are key to the regulation of on-going pain states(10-13). Pioneering studies in rats and companion $\operatorname{dogs}(11,14)$ showed that persistent pain states can be ameliorated by using a saporin-substance $\mathrm{P}$ conjugate to ablate a small population of spinal substance $\mathrm{P}$ receptor (NK1R) expressing projection neurons that convey pain-related information to the brain. In order to circumvent of the problem of killing spinal neurons with saporin, we designed botulinum conjugates that were safe to construct, non-toxic and acted relatively quickly after intrathecal injection to silence pain processing neurons in the spinal $\operatorname{cord}(15,16)$.

Botulinum toxin A is made up of a light chain zinc endopeptidase and a heavy chain that is responsible for binding the toxin to neuronal receptors and promoting essential light-chain translocation across the endosomal membrane(17). Once internalized within the neuron, the light chain has the capacity to silence neurons for several months via the specific proteolytic cleavage of synaptosomal-associated protein 25 (SNAP25) a protein essential for synaptic release $(15,16,18)$. This inhibition is slowly reversed as the endopeptidase loses activity(17). cSNAP25 is found in neurons but not glial cells and is the unique substrate for botulinum protease cleavage $(19,20)$. We exploited a recently introduced 'protein stapling' method $(15,18)$ using SNARE (Soluble $\mathrm{N}$-ethylmaleimide sensitive factor Attachment protein Receptor complex) proteins to link the light chain/translocation domain (LCTd) of botulinum neurotoxin type A (BOT) to neurotransmitter ligands substance $\mathrm{P}$ and dermorphin that target pain processing neurons in the dorsal horn. In order to 
silence NK1R-expressing neurons, we used a substance P-botulinum (SP-BOT) construct previously developed(15) while mu opiate receptor expressing neurons were silenced using a dermorphin-botulinum construct. We found that the new constructs were selectively internalized following binding to their target receptors, silenced neurons and produced a long-term amelioration of pain states.

\section{RESULTS}

SP botulinum conjugate induces long-term reduction of inflammatory and neuropathic pain sensitivity in mice.

In order to silence NK1R-expressing neurons, we used a substance P-botulinum (SPBOT) construct previously developed (15). SP-BOT (Fig. S1) was injected intrathecally (i.t.) over the lumbar spinal cord of adult C57BL6/J male mice. Hind paw mechanical withdrawal thresholds measured with von Frey filaments were used as an indicator of analgesia. The i.t. injection of SP-BOT had no effect on baseline mechanical threshold in naïve mice tested over 7 days (Fig. 1A) and produced no signs of motor impairment assessed by plantar spreading or rotarod performance (Fig. 1B). However, in two models of inflammatory pain induced by ankle or hind paw injection of complete Freund's adjuvant (CFA), i.t. injection of SP-BOT 2 days after CFA (when mice showed increased pain sensitivity) produced a substantial reduction in mechanical hypersensitivity that accompanied inflammation (Fig. 1C, D). One single i.t. injection was effective in reducing pain sensitivity for the duration of the experiment ( 21 days for the ankle model and 12 days for the hind paw model). As internal control, in the hind paw model we showed that threshold of mechanical 
allodynia in the contralateral paw was unchanged (Fig.S2A). Dose response experiments in animals that received an ankle injection of CFA showed that maximal reduction of pain sensitivity was obtained with i.t injection of 100ng of SP-BOT (Fig. S3A).

Intrathecal injections of the unconjugated BOT without a receptor-binding domain (Light-chain translocation domain, LcTd), had no effect on mechanical hypersensitivity following injection of CFA in the ankle (Fig. S4).

We next investigated the effect of SP-BOT on neuropathic pain by testing the mechanical sensitivity in the unilateral (left) spared nerve injury (SNI) model of neuropathic pain (pain that is derived from peripheral nerve damage). The lesion induced hypersensitivity in the lateral area of the paw on the left side, which is innervated by the spared sural nerve. SP-BOT was injected i.t. when the mechanical hypersensitivity was fully developed and we observed a reduction in mechanical hypersensitivity that begun around $3 \mathrm{~d}$ after SP-BOT injection and lasted for the duration of the experiment (22 days) (Fig. 1E). Mechanical thresholds for the contralateral paw (right) were unchanged (Fig.S2B). To confirm the essential role of NK1R in mediating the effects of SP-BOT induced reduction of mechanical pain sensitivity, we used NK1R knockout mice $\left(\mathrm{NK}_{1} \mathrm{R}^{-/-)}\right.$(21) Neuropathic mechanical hypersensitivity was similar in $\mathrm{NK}^{-/-}$and wild type (WT) littermates after SNI. Intrathecal injection of SP-BOT was effective in alleviating mechanical hypersensitivity only in WT animals, whereas in $\mathrm{NKRI}^{-/-}$mice mechanical allodynia 
was not affected by SP-BOT injection (Fig. 1F). The results indicate that the NK1R is essential for SP-BOT mediated reduction of mechanical pain hypersensitivity.

\section{SP-BOT is internalized only by NK1-receptor expressing neurons but does not cause} cell death.

The specificity of the targeted toxin was investigated by examining the distribution of cleaved SNAP 25 (cSNAP25) (Synaptosomal-associated protein of 25kDa) using immunohistochemistry in spinal cord tissue sections using an antibody specific for cSNAP25 (22). Tissue was taken from CFA-treated mice that had received i.t. injections of SP-BOT, CFA-treated animals that received i.t saline injection and naïve animals ( $n=4$ per group). Double fluorescent immunohistochemistry for cSNAP25 and NK1R indicated that the SP-BOT construct was expressed in cell bodies and axonal and dendritic branches of NK1R positive neurons(Fig. 2A, B). Cell bodies were first seen $96 \mathrm{~h}$ after i.t. injection of the construct and the numbers and distribution of labelled cell bodies within the superficial dorsal horn remained unchanged for the duration of the experiment and was unaffected by peripheral treatment (Fig. S5). Analysis of the parabrachial nucleus (PB) of the hindbrain-the major site of termination of NK1R positive spinal projection neurons $(23,24)$-revealed cSNAP25positive putative axons in all mice injected 14 days previously with i.t. SP-BOT, but not in saline-injected controls (Fig. 2C). As NK1R is not found in axons(25), the results suggest that there had been axonal transport of CSNAP25 and/or botulinum protease following uptake of the SP-BOT conjugate by spinal NK1R positive dendrites and cell bodies. Immunohistochemistry measuring c-Fos expression, a marker of cell

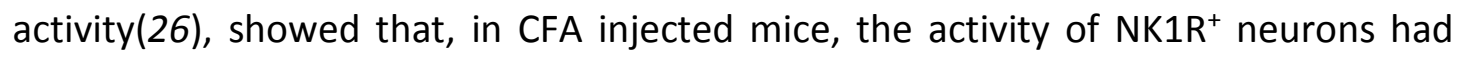


been reduced in the parabrachial area of mice that had received an i.t. injection of

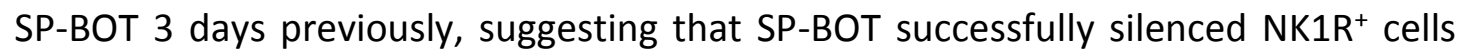
(Fig. 2D). In naïve mice there was no evidence of microglial or astrocytic activation following SP-BOT treatment (Fig. S6). Also, no changes in the extent of NK1Rpositive immunofluorescence were found in the dorsal horn of mice that had been treated with SP-BOT suggesting lack of construct-induced cytotoxicity or receptor down-regulation (Fig. 2E).

\section{Dermorphin-botulinum conjugate alleviates long-term pain states.}

Opioids such as morphine are effective in relieving chronic pain. Their analgesic properties are mostly mediated by the mu opioid receptor $(\mathrm{MOR})(27)$. In the dorsal horn MOR is expressed by interneurons and some primary afferents and by some projection neurons(28-30).

To test the possibility that inhibiting MOR-expressing neurons could promote analgesic effects, we conjugated the botulinum toxin to the MOR agonist dermorphin $(31,32)$ (Derm-BOT) and compared the analgesic efficacy of Derm-BOT with morphine.

Derm-BOT has been injected i.t at the optimal dose of $100 \mathrm{ng} / 3 \mathrm{ul}$ in naïve mice and in mice previously injected with CFA in the ankle joint or in the hind paw after increased mechanical pain hypersensitivity was established. Derm-BOT injection did not affect mechanical pain sensitivity in naïve control mice (Fig. 3A); in contrast, we observed a reduction in the mechanical hypersensitivity that lasted until the end of the experiments (up to 18 days) in both models of inflammatory pain (Fig. 3B,C). 
Furthermore when Derm-BOT was injected after SP-BOT, the reduction in pain sensitivity induced by SP-BOT was not further augmented (Fig. 3D). We then investigated the effect of Derm-BOT on the hypersensitivity that develops after SNI surgery and found that a single i.t. injection of the construct alleviated the mechanical hypersensitivity for the duration of the experiment (23 days) (Fig. 3E).

Dermorphin-botulinum conjugate was internalized by MOR positive neurons and did not induce toxicity.

Immunohistochemical analysis of spinal cord sections from Derm-BOT injected mice showed that all cSNAP25-positive cell bodies and many neuronal processes throughout the dorsal horn were stained with MOR antibody (Fig. 4A, B) but there was no labelling of axons in the dorsal roots. Cell bodies were first seen $96 \mathrm{~h}$ after i.t. injection of the construct and the numbers and distribution of cSNAP25 labelled cell bodies remained unchanged for the duration of the experiment (Fig. S5). These results indicated that CSNAP25 positive cell bodies and fibers were likely to be MORpositive local neurons (Fig. 4 A, B) and that MOR positive primary afferents did not internalize the construct. We also failed to find evidence for glial activation in naïve mice treated with Derm-BOT (Fig. S6). As with SP-BOT, no indication of toxicity was found after Derm-BOT injection (Fig. S7).

\section{Dermorphin-botulinum conjugates replicate the analgesic actions of morphine}

Finally, we compared the effects on mechanical pain sensitivity of Derm-BOT with morphine $(5 \mathrm{nmol})(33)$ in the SNI mouse model. Intrathecal Derm-BOT reduced 
mechanical sensitivity in SNI mice to the same extent as i.t. morphine and no additive effects were seen when morphine was injected i.t into mice pre-treated with Derm-BOT (Fig. 5A). This implied that pre-treatment with Derm-BOT silenced many of the MOR expressing neurons in the lumbar dorsal horn. Derm-BOT also generated analgesia in $\mathrm{NK}^{-1} \mathrm{R}^{--}$mice (Fig. 5B) whereas SP-BOT was ineffective, confirming the specificity of the botulinum constructs.

\section{DISCUSSION}

There is an urgent need for new pain-relieving therapies(34). Here we used animal models of inflammatory and neuropathic pain to show that a single injection of compounds derived from botulinum toxin can silence pain-processing neurons in the spinal cord and decrease pain hypersensitivity. In two sets of experiments we targeted NK1R expressing neurons that relay pain-related information from the spinal cord to the brain and the MOR-expressing spinal cells that modulate activity of NK1R-expressing output neurons $(10,30,35)$. We describe a long-term effect on mechanical pain sensitivity on both inflammatory and neuropathic pain states, following a single injection of the constructs and demonstrate in vivo receptor specificity. We found no additive effects of SP-BOT and Derm-BOT, suggesting that although the constructs silence different neurons, they are likely to be part of the same neural pain network with MOR-expressing excitatory neurons modulating NK1R positive projection neurons. As such these new botulinum constructs would appear to be equally useful in reducing pain hypersensitivity .

Among the seven types (A-G) of botulinum toxin that target neurons, due to its longlasting activity and high efficiency, Botulinum toxin serotype A (BoNT/A) has been 
approved by the FDA for treating a variety of disorders(36-40). In neuronal cultures, the proteolytic activity of BoNT/ persists beyond 80 days whereas other subtypes of BoNT have shorter half-lives $(37,41)$. Peripheral injections of botulinum neurotoxins have been shown to reduce both neuropathic pain and the frequency of migraine attacks in human patients(42-44). This anti-nociceptive action has been exploited by a number of groups $(44,45)$;more recently, using a synthetic procedure it was possible to separate the pain relieving from the paralyzing actions by synthesizing peptide components of BoNT/A and 're-stapling' them into a unique configuration $(15,16)$. Systemic administration of these reassembled molecules was shown to inhibit neuronal activity without causing toxicity (18). To generate the botulinum-based molecules we used a synthesis procedure that allowed nonchemical linking of recombinantly produced proteins using core components of the SNARE complex to achieve irreversible linkage of two separate peptide fragments into a functional unit(16). This approach was particularly important as the production of functional botulinum-based molecules has significant safety issues due to protein toxicity. The assembly of the functional toxin from innocuous parts is therefore an important advance as safety issues have severely restricted the development of botulinum-derived molecules for medical use.

We generated new molecules by substituting the non-specific neuronal binding targeting domain of BoNT/A with ligands that recognize the key $\mathrm{G}$ protein-coupled neurotransmitter receptors NK1R and MOR. Binding to these receptors was followed by internalization of the construct and, because of the inclusion of the translocation domain into our constructs, release of the protease domain of the toxin into the 
cytoplasm and inhibition of synaptic release. The synthesis of SP-BOT has been previously described (15) but to synthesize the Derm-BOT construct required further synthetic steps. Dermorphin is a potent selective opioid mu receptor agonist (31, 32, 46)and has been successfully used previously in saporin conjugates to selectively ablate MOR-expressing neurons(13). Conjugation of dermorphin to the LcTd portion of botulinum was complicated because dermorphin binds to the receptor through its $\mathrm{N}$-terminus, the portion of the molecule generally used for the botulinum conjugation procedure(16). To circumvent this problem we introduced a synthetic inversion procedure (see Methods) that allowed conjugation of dermorphin to the LCTd portion of botulinum toxin while retaining the free $\mathrm{N}$ terminus of dermorphin for binding to the mu opiate receptor, followed by internalization and SNAP25 cleavage.

It is likely that the separation of the botulinum translocation domain from the neuropeptide ligands using the 'stapling' mechanism allowed sufficient freedom for the translocation domain to perform the $\mathrm{pH}$-dependent structural transition necessary to facilitate transfer of the botulinum protease from the luminal space of vesicle into the neuronal cytosol. However, it has been reported(47) that attachment of SP directly to botulinum protease allowed entry into neurons and SNAP25 cleavage. Omission of the obligatory translocation domain from the construct suggests that the activity would have been suboptimal and may account for the short in vivo efficacy(47).

SNAP25, the unique substrate for botulinum peptidase activity, is found throughout dendrites, where a role in spine morphogenesis has been proposed (48), as well as in 
cell bodies and axons. NK1R receptors are located on dendrites and cell bodies while MOR is also found on axons and axon terminals and binding and internalization would be expected at most receptor binding sites $(25,49,50)$. Given the lack of axonal NK1R expression, the presence of cleaved cSNAP25 in spinal to brainstem axons following spinal treatment with SP-BOT was most likely the result of cleavage of SNAP25 in NK1R-positive dendrites and cell bodies in the dorsal horn followed by axonal transport of cSNAP25 and/or the protease to the synaptic terminals within the brainstem.

NK1R expressing spinal projection neurons have been shown to be essential for the maintenance of pain states (11). Information related to injury reaches the brain largely through NK1R-positive projection neurons of the superficial dorsal horn that terminate massively in the parabrachial area of the brainstem and to a lesser extent within the thalamus $(35,51)$. The parabrachial area is crucial for supplying information to forebrain areas that generate the affective-motivational component of pain $(52,53)$ whereas thalamic afferents terminate within cortical areas concerned with both pain discrimination and affect(51). Forebrain activation can in turn regulate dorsal horn sensitivity by activating descending controls from the brainstem to the spinal cord $(3,12,54)$. Thus a shift in the balance between pain inhibiting and facilitating controls from the brainstem, informed by NK1R-positive dorsal horn projection neurons, plays a role in setting spinal nociceptive thresholds required by on-going behavioural priorities and may ultimately contribute to pathological pain states(54). It follows that the inflammatory and neuropathic mechanical allodynia is disrupted by intrathecal ablation or silencing of these NK1R-expressing projection neurons with substance P-saporin (11) or SP-BOT constructs respectively. Recent 
work has shown that chemotoxic ablation of the NK1R-positive pain pathway in companion dogs can relieve bone cancer pain(14) demonstrating the applicability of the approach to higher mammals in different pain subtypes.

The disadvantage of the substance P-saporin procedure is that it takes several weeks to become effective and kills neurons $(11,14)$. Our intention was to design a reversible and non-toxic molecule that would achieve the same analgesia, rapidly and without cell death. The approach described here using SP-BOT silences NK1R expressing neurons without cell death and is effective in days rather than weeks; in addition, SP-BOT is relatively easy to synthesize. As expected the analgesic effect of SP-BOT constructs was completely lost in NK1R knockout mice.

MOR is expressed by dorsal horn interneurons and found in some small diameter primary afferent sensory fibers $(49,55,56)$. However, previous research has implied that the opioid tolerance and opioid-induced hyperalgesia that follow repeated injections of morphine are mediated by primary afferent MORs(55). It was also shown that i.t. morphine produced strong mechanical and thermal antinociception in naive mice but that was lost in mice in which MOR had been deleted only from primary afferents(55) suggesting that spinal neurons expressing mu opiate receptors did not play a role in setting baseline mechanical thresholds or the generation of analgesic tolerance following repeated injections of morphine. However, intrathecal Derm-BOT in the naïve mice reported here, had no effect on baseline mechanical pain sensitivity but only on mechanical thresholds in injury-induced pain states. This suggests that the target for Derm-BOT mediated analgesia was not primary afferents 
expressing MOR, but MOR positive dorsal horn neurons. A similar result was reported in rats following the partial ablation of MOR expressing neurons with dermorphin-saporin (Derm-SAP) conjugates(57) raising the possibility that presynaptic opiate receptors may not internalise after opiate agonist administration(58).

Currently, new approaches to the control of chronic pain have adopted both central intrathecal and peripheral systemic approaches. Intrathecal opioids and other drugs are often given in clinical practice to relieve chronic pain when other treatment routes are exhausted or to circumvent the inherent risks of long-term systemic opioid treatment. However, intrathecal administration requires a surgicallyembedded pump to administer a prolonged infusion of the drug to the spinal $\operatorname{cord}(59,60)$. Intrathecal treatments primarily target and inhibit central sensitization, the driving force behind chronic pain states. Unfortunately, long-term intrathecal opioid administration can result in respiratory depression, i.t. granuloma, opioid tolerance and other serious side effects(61). Moreover, although systemic opioids remain the gold standard for pain control, there are major concerns around the problems of drug overdose and addiction in part due to the relaxation of prescribing of opioids for non-terminal chronic pain(9). Conjugates of the silencing domain of botulinum toxin with SP or dermorphin provide substantial analgesia without evident toxic effects and over long periods of time following a single i.t. injection. Complete analgesia is not entirely desirable. As clinical studies with anti-nerve growth factor antibodies have demonstrated encouraging the use of an already damaged limb may have resulted in further damage leading to hip or knee replacement $(62,63)$. The successful use of SP-saporin in rodents and dogs also 
opens up the possibility that silencing of this pathway with SP-BOT might be sufficient to control chronic pain states in human patients without permanent damage to the spinal $\operatorname{cord}(11,14)$.

Also, the side effects of chronic opioid use including analgesic tolerance, paradoxical opioid-induced hyperalgesia and addiction(64) might be avoided by a single intrathecal injection of the dermorphin-botulinum construct.

Translating knowledge from preclinical observations in animal models of pain states to new therapies in the clinic has been difficult and has met with limited success. Differences between animal behavioural tests and human chronic pain features, particularly the assessment of both sensory and affective features of the pain state, as well as measurements of long-term efficacy and species variability may have been confounding factors(6). Nevertheless the successful translation of the substance Psaporin treatment from rats to companion dogs with bone cancer pain suggests(11, 14) there is potential for the introduction of botulinum-based silencing approaches for the control of pain without cytotoxicity or recourse to repeated treatment of analgesics that can produce adverse behavioural effects.

\section{METHODS}

\section{Study Design}

This study was designed to evaluate the effect of SP-BOT and Derm-BOT on pain sensitivity. In behavioural studies, mice were randomly assigned to experimental groups. The experimenter was always blind to treatment and genotype. We could 
not predict a priori the effect size for the botulinum constructs and were guided by Mead's Resource equation. Therefore, we aimed to use at least 6 mice in each group and no more than 11 . Occasionally mice were excluded from the study if they were found to have bodily damage from fighting with cage mates (5 out of 206 total mice were discarded). We did perform statistical analysis at the end of each round of experiments in order to satisfy the 3Rs which dictates that "The number of animals used should be the minimum number that is consistent with the aim of the experiment" (https://www.nc3rs.org.uk/the-3rs).

\section{Mice}

Subjects in all experiments were adult mice (8-12 weeks old). Wild-type (WT) mice were C57BL/6 from Envigo. NK1R KO (NKR1 $\left.{ }^{--}\right)$and WT littermates were obtained from a colony of mice derived from a 129/Sv $\times$ C57BL/6 genetic background(21). NKR1 ${ }^{-/}$mice were backcrossed with a wild type C57/B6 mouse for several generations. Experiments were always carried out using littermates from heterozygous breeding pairs. All mice were kept in their home cage in a temperature-controlled $\left(20 \pm 1^{\circ} \mathrm{C}\right.$ ) environment, with a light-dark cycle of $12 \mathrm{~h}$ (lights on at 7:30 a.m.). Food and water were provided ad libitum. All efforts were made to minimize animal suffering and to reduce the number of animals used (UK Animal Act, 1986).

\section{Genotyping}

For genotyping, DNA was extracted from ear tissue, and the following primers were used for PCR: forward NK1R primer, CTGTGGACTCTAATCTCTTCC; reverse NK1R 
primer ACAGCTGTCATGGAGTAGATAC; Neomycin-resistant gene (NeoF) primer GCAGCGATCGCCTTCTATC. Samples from WT mice showed a single PCR (Polymerase Chain Reaction) product of 350 base pairs (bp); samples from NKR1 ${ }^{-/}$mice showed a single PCR product of $260 \mathrm{bp}$; and samples from heterozygous mice would present both bands(21).

\section{Design and purification of botulinum constructs}

Each BoNT/A consists of three domains: the binding domain (Bd), the translocation domain (Td), and the catalytic light-chain domain (Lc), a zinc metallopeptidase. We utilized a protein stapling technique to produce light chain and translocation domain (LCTd) conjugated to substance $\mathrm{P}$ or dermorphin, a naturally occurring mu-opioid agonist which carries an unnatural D-amino acid, making it resistant to internal proteolysis. The synthesis has been described previously for SP with in vitro controls for specificity detailed(15). Briefly, to synthesize the constructs:

a) a fusion protein consisting of the LcTd of the botulinum type A1 strain was fused to SNAP25 (LcTd-S25) and was prepared as previously described $(16,65)$. The chemically synthesised syntaxin-SP peptide had the sequence:

\section{Ac-EIIKLENSIRELHDMFMDMAMLVESQGEMIDRIEYNVEHAVDYVE-Ahx-Ahx-}

RPKPQQFFGLM-NH2, where Ahx stands for aminohexanoic acid. Due to the need for the N-terminus of dermorphin to be accessible for binding to the MOR, the syntaxindermorphin peptide was synthesized in two parts, syntaxin-maleimide and dermorphin-cysteine, which were then bio-orthogonally conjugated through two reactive C-termini. The dermorphin and syntaxin sequences were respectively: YaFGYPS and EIIRLENSIRELHDMFMDMAMLVESQGEMIDRIEYNVEHAVDYVEK. 
b) The protein 'staple' was prepared recombinantly from the rat VAMP2 sequence (aa 3-84) inserted into the Xhol site of pGEX-KG. Oriented attachment of peptides to protein was achieved by the SNARE assembly reaction. LcTd-S25, VAMP2 (3-84) and either syntaxin-dermorphin or syntaxin-SP were mixed at a molar ratio of 1:1:1 in $100 \mathrm{mM} \mathrm{NaCl}$ (Sodium Chloride), 20 mM HEPES (4-(2-hydroxyethyl)-1piperazineethanesulfonic acid) and 0.4\% n-octylglucoside (OG), at pH 7.4 (Buffer A). Reactions were left at $20^{\circ} \mathrm{C}$ for 1 hour to allow formation of the SNARE ternary complex. Sodium dodecyl sulfate (SDS)-resistant and irreversibly assembled protein conjugates were visualised using Novex NuPAGE $12 \%$ Bis-Tris SDS-PAGE (Polyacrylamide Gel Electrophoresis) gels (Invitrogen) run at $4^{\circ} \mathrm{C}$ in NuPAGE MES SDS running buffer (Invitrogen). All recombinant proteins were expressed in the BL21Gold-PLysS-DE3 strain of Escherichia coli (Agilent) in pGEX-KG vectors as glutathioneS-transferase (GST) C-terminal fusion proteins cleavable by thrombin. GST fusion constructs were purified by glutathione affinity chromatography and cleaved using thrombin. Synthetic peptides were made by Peptide Synthetics, Ltd.

\section{Cortical cultures}

To confirm construct efficacy rat cortical neurones were dissected from 8-12 embryonic day 17 rat pups and washed in Hanks' Balanced Salt Solution (HBSS), before being treated with trypsin for $15 \mathrm{~min}$ at $37^{\circ} \mathrm{C}$, followed by addition of DNase (Sigma). Cells were resuspended in $1 \mathrm{ml}$ triturating solution (1\% Albumax (Gibco), 0.5 $\mathrm{mg} / \mathrm{mL}$ Trypsin inhibitor (Sigma), $1 \mu \mathrm{g} / \mathrm{mL}$ DNase in HBSS). Cells were triturated using three progressively smaller glass pipettes before being diluted to $5 \mathrm{ml}$ by the addition of cortical medium. 50,000 cells in $150 \mu$ l medium were plated on 96 -well plates 
coated with poly-D-lysine. Cells were maintained in neurobasal medium (Gibco) supplemented with 1\% B27 (Gibco), 1\% P/S, and 1\% GlutaMAX (Gibco)) Half the medium was changed every 3-4 days and cultures were tested between 1 and 3 weeks after plating.

\section{Western analysis of botulinum activity}

Derm-BOT and SP-BOT (400 nM in Buffer A (100 mM NaCl, 20 mM HEPES)) were added to the plated cortical cells at a 1:20 dilution to achieve the final concentration of $20 \mathrm{nM}$. Cells were incubated at $37^{\circ} \mathrm{C}$ and $5 \% \mathrm{CO}_{2}$ for $65 \mathrm{~h}$ before culture media was removed and $20 \mu \mathrm{l}$ of loading buffer ( $56 \mathrm{mM}$ sodium dodecyl sulfate, $0.05 \mathrm{M}$ Tris- $\mathrm{HCl}$, pH6.8, $1.6 \mathrm{mM}$ UltraPure EDTA (Gibco), 6.25\% glycerol, 0.0001\% bromophenol blue, $10 \mathrm{mM} \mathrm{MgCl}$, $26 \mathrm{U} / \mathrm{mL}$ benzonase (Novagen)) was added to each well. Plates were shaken at $900 \mathrm{rpm}$ for $10 \mathrm{~min}$ at $20^{\circ} \mathrm{C}$ and samples were transferred to a fresh $0.5 \mathrm{ml}$ tube. Samples were boiled for $3 \mathrm{~min}$ at $95^{\circ} \mathrm{C}$ and then run on Novex NuPAGE $12 \%$ Bis-Tris SDS-PAGE gels (Invitrogen). Following separation, proteins were transferred onto immobilin-P polyvinylidene difluoride membranes, and then incubated for $30 \mathrm{~min}$ in blotting solution $(5 \%$ milk, $0.1 \%$ TWEEN 20 in PBS). Mouse monoclonal SMI81 antibody (anti-SNAP25) was added at 1:2000 dilution to the blotting solution at $4^{\circ} \mathrm{C}$ for overnight incubation. Membranes were washed three times in 0.1\% TWEEN 20 in PBS for 5 min and then incubated for $30 \mathrm{~min}$ in the blotting solution containing secondary peroxidase-conjugated donkey anti-rabbit antibody (Amersham) at a 1:2400 dilution. Membranes were washed three times for $5 \mathrm{~min}$ in $0.1 \%$ TWEEN 20 in PBS. Immunoreactive protein bands were visualized using SuperSignal West Dura Extended Duration solution (Thermo 
Scientific, Cramlington, UK) with exposure to Fuji Medical X-ray films (Fuji, Ross-onwye, UK).

\section{Behavioural testing}

\section{$\underline{\text { Von Frey filament test }}$}

The experimenter was always blind to genotype and treatment group for all behavioural tests. Animals were placed in Plexiglas chambers, located on an elevated wire grid, and allowed to habituate for at least 1 hour. After this time, the plantar surface of the paw was stimulated with a series of calibrated von Frey's monofilaments. The threshold was determined by using the up-down method(66) The data are expressed as log of the mean of the $50 \%$ pain threshold \pm SEM. In some cases the data was plotted as force (g) (Fig S8 and S9).

\section{Rotarod test}

Motor performance was evaluated by an accelerating rotarod apparatus with a 3$\mathrm{cm}$-diameter rod starting at an initial rotation of $4 \mathrm{rpm}$ and slowly accelerating to 40 rpm over $100 \mathrm{~s}$. Mice were expected to walk at the speed of rod rotation to keep from falling. The time spent on the rod during each of two trials per day was measured and expressed in seconds. Animals were tested only once at baseline to minimize the number of tests on the rotarod. Testing was completed when the mouse fell off the rod (that is, from a height of $12 \mathrm{~cm}$ ).

\section{Pain models}




\section{Mouse inflammatory models}

\section{$\underline{\text { CFA-induced ankle joint inflammation }}$}

Inflammation was induced by injection of $5 \mu \mathrm{l}$ of Complete Freud's Adjuvant (CFA; Sigma) into the left ankle joint under isoflurane anaesthesia induced in a chamber delivering $2 \%$ isoflurane combined with $100 \% \mathrm{O}_{2}$ and maintained during injection via a face mask. The needle entered the ankle joint from the anterior and lateral posterior position, with the ankle held in plantar flexion to open the joint(67).

\section{CFA-induced hind paw inflammation}

CFA $(20 \mu l)$ was injected using a micro-syringe with a 27-gauge needle subcutaneously into the plantar surface of the left hind paw. Mice were maintained under isoflurane anaesthesia during the injection.

\section{Mouse neuropathic model: spared nerve injury}

The spared nerve injury (SNI) was performed as previously described(68). Briefly, under isoflurane anaesthesia the skin on the lateral surface of the thigh was incised and a section made directly though the biceps femoris muscle, exposing the sciatic nerve and its three terminal branches: the sural, the common peroneal and the tibial nerves. The common peroneal and the tibial nerves were tight-ligated with 5-0 silk and sectioned distal to the ligation. Great care was taken to avoid any contact with the spared sural nerve. Complete hemostasis was confirmed and the wound was sutured.

\section{Intrathecal injections}


Intrathecal injections were performed under anaesthesia(69). The mice were held firmly, but gently, by the pelvic girdle using thumb and forefinger of the nondominant hand. The skin above the iliac crest was pulled tautly to create a horizontal plane where the needle was inserted. Using the other hand, the experimenter traced the spinal column of the mouse, rounding or curving the column slightly to open the spaces between vertebrae. A 30-gauge needle connected to a $10 \mu \mathrm{l}$ Hamilton syringe was used to enter between the vertebrae. After injection, the syringe was rotated and removed and posture and locomotion were checked. All intrathecally delivered drugs were injected in a $3 \mu$ volume.

\section{Immunohistochemistry}

Mice were deeply anesthetized with pentobarbital and perfused transcardially with physiological saline containing $5000 \mathrm{IU} / \mathrm{ml}$ heparin followed by $4 \%$ paraformaldehyde (PFA) in $0.1 \mathrm{M}$ phosphate buffer (PB; $25 \mathrm{ml}$ per adult mouse). Lumbar spinal cords were dissected out, fixed in 4\% PFA for an additional $2 \mathrm{~h}$, and transferred into a $30 \%$ sucrose solution in $\mathrm{PB}$ containing $0.01 \%$ azide at $4^{\circ} \mathrm{C}$, for a minimum of $24 \mathrm{~h}$. Spinal cord sections were cut on a freezing microtome set at $40 \mu \mathrm{m}$. For fluorescent immunohistochemistry, sections were left to incubate with primary antibodies $\mathrm{O} / \mathrm{N}$ at room temperature (anti-cSNAP25 antibody recognizing the cleaved end of SNAP25 1:50,000 ref, TRIDEANQ; anti-NK1, guinea pig, 1:10,000, Neuromics; anti-MOR, rabbit, 1:10,000, Neuromics). For NK1 and MOR immunohistochemistry, direct secondary antibody was used at a concentration of 1:500 (Alexa Fluor). For CSNAP25 staining, appropriate biotinylated secondary antibody was used at the concentration of 1:400 and left for 90 min. Sections were 
then incubated with avidin-biotin complex (ABC Elite, Vector Lab; 1:250 Vectastain A plus 1:250 Vectastain B) for 30 min followed by a signal amplification step with biotinylated tyramide solution (1:75 for 7 min; Perkin Elmer). Finally, sections were incubated with FITC-avidin for 2 h (1:600). An antibody against Iba1 (lonized calcium binding adaptor molecule 1, Goat, 1:500 overnight, Abcam) was used to identify microglia and an anti-GFAP antibody to stain for astrocytes (Glial fibrillary acidic protein, rabbit, 1:4000, overnight, Dako) using immunohistochemistry. The direct secondary antibody was used at a concentration of 1:500 (Alexa Fluor). All fluorescent sections were transferred to glass slides and cover slips applied with Gel Mount Aqueous Mounting Medium (Sigma) to prevent fading, and stored in dark boxes at $4^{\circ} \mathrm{C}$. In co-labelling studies, controls included omission of the second primary antibody.

\section{Quantification of fluorescence}

For quantification of NK1R- and MOR-fluorescence, a region of interest (ROI) was located over laminae I/II. The ROI was $3087 \mu \mathrm{m}^{2}$ for NK1R and $1617 \mu \mathrm{m}^{2}$ for MOR immunostained tissue. Fluorescence was measured for six sections per animal using the same ROI. Readings were taken from the side of the spinal cord contralateral to the inflamed paw or nerve lesion. Contrast enhancement and fluorescence threshold were kept constant. Readings from saline and botulinum construct i.t. injected mice were compared.

\section{c-Fos immunohistochemistry}


c-Fos immunohistochemistry was used to assess the silencing of the lamina 1 NK1R positive neurons. Preemptive i.t. treatment with SP-BOT in naïve mice was followed 3 days later by an injection of CFA into the left paw under isoflurane anaesthetic. $6 \mathrm{~h}$ later animals were perfused and processed for c-Fos expression in the lateral parabrachial area. For DAB (3,3' - Diaminobenzidine), sections were blocked in PB with $3 \%$ serum, $3 \%$ triton and $2 \% \mathrm{H} 2 \mathrm{O} 2$ for one hour, and then incubated over weekend with the primary antibody (anti c-Fos, rabbit, 1:10000, Millipore Merck KGaA). The sections were then incubated in appropriate secondary antibody at 1:500 for 2 hours, followed by incubation with avidin biotin complex (ABC Elite, Vector Lab; 1:1000 Vectastain A plus 1:1000 Vectastain B) for 1 hour. The substrate was then developed using a peroxidase substrate DAB kit (Vector \#SK4100) at optimised times, and the sections were washed and mounted. The following day, the sections were dehydrated in increasing ethanol concentrations (70\%, 70\%, 95\%, 95\%, 100\%, 100\%, histoclear $\times 2$ ) and coverslipped with DPX.

Five sections through the PBN from each mouse were analysed for population density of c-Fos neurons. cFos-immunoreactive neurons were counted in the lateral parabrachial area bilaterally. Counts from the sections were averaged and the mean was used for further statistical analysis. To quantify cSNAP positive neuronal cell bodies 4 spinal cord sections from each mouse were counted. Means were taken for each treatment for further analysis. Counts were from laminae I-III of the dorsal horn.

\section{Statistical analysis}


All statistical tests were performed using the IBM SPSS statistics programme, version 20, and $\mathrm{P}<0.05$ was considered statistically significant. For the behavioural experiments, statistical analysis was performed on the data normalized by log transformation (von Frey data) as suggested by Mills et al.,(70) Difference in sensitivity was assessed using repeated-measured two-way or one-way analysis of variance (ANOVA), as appropriate and as indicated. In all cases, a significant effect of the main factor(s), or interactions between them, was taken as the criterion for progressing to post hoc analysis. Bonferroni correction was the preferred post hoc approach, when we had 3 groups or more; in this case, if the general ANOVA was significant but no Bonferroni significance observed, we also reported the results of the least significant difference post hoc analysis. When we had 2 groups, we report the result of the one-way ANOVA. In all cases 'time' was treated as a within-subjects factor, and 'genotype' and 'treatment' were treated as between-subject factors. The statistical significance in fig 2D was determined using one-way ANOVA followed by LSD (Fisher's Least Significant Difference) test.

The Maximum Possible Effect (MPE) was calculated as:

$\% \mathrm{MPE}=\frac{100 *[\log (\text { drug induced threshold })-\log (\text { vehicle induced threshold })]}{[\log (0,6)-\log (\text { vehicle induced threshold })]}$

Where $\log (0.6 \mathrm{~g})$ is our maximum Von Frey's force applied.

Please note that, as in our previous paper (67), we logged the data of the behavioural testes to ensure a normal distribution since the Von Frey's hairs are distributed on an exponential scale. Mills et al, 2012, recently demonstrated that Log transformation makes more 'mathematical and biological sense' (62). 


\section{References}

1. P. D. Wall, On the relation of injury to pain. The John J. Bonica lecture. Pain 6, 253-264 (1979).

2. M. S. Gold, G. F. Gebhart, Nociceptor sensitization in pain pathogenesis. Nat Med 16, 1248-1257 (2010).

3. R. Kuner, Central mechanisms of pathological pain. Nat Med 16, 12581266 (2010).

4. C. Torsney, Inflammatory pain unmasks heterosynaptic facilitation in lamina I neurokinin 1 receptor-expressing neurons in rat spinal cord. $J$ Neurosci 31, 5158-5168 (2011).

5. A. D. Weyer, K. J. Zappia, S. R. Garrison, C. L. O'Hara, A. K. Dodge, C. L. Stucky, Nociceptor Sensitization Depends on Age and Pain Chronicity(1,2,3). eNeuro 3, (2016).

6. L. Colloca, T. Ludman, D. Bouhassira, R. Baron, A. H. Dickenson, D. Yarnitsky, R. Freeman, A. Truini, N. Attal, N. B. Finnerup, C. Eccleston, E. Kalso, D. L. Bennett, R. H. Dworkin, S. N. Raja, Neuropathic pain. Nat Rev Dis Primers 3, 17002 (2017).

7. T. J. Price, M. S. Gold, From Mechanism to Cure: Renewing the Goal to Eliminate the Disease of Pain. Pain medicine, (2017).

8. N. B. Finnerup, N. Attal, S. Haroutounian, E. McNicol, R. Baron, R. H. Dworkin, I. Gilron, M. Haanpaa, P. Hansson, T. S. Jensen, P. R. Kamerman, K. Lund, A. Moore, S. N. Raja, A. S. Rice, M. Rowbotham, E. Sena, P. Siddall, B. H. Smith, M. Wallace, Pharmacotherapy for neuropathic pain in adults: a systematic review and meta-analysis. The Lancet. Neurology 14, 162173 (2015).

9. N. D. Volkow, A. T. McLellan, Opioid Abuse in Chronic Pain-Misconceptions and Mitigation Strategies. N Engl J Med 374, 1253-1263 (2016).

10. S. P. Hunt, P. W. Mantyh, The molecular dynamics of pain control. Nat Rev Neurosci 2, 83-91 (2001).

11. M. L. Nichols, B. J. Allen, S. D. Rogers, J. R. Ghilardi, P. Honore, N. M. Luger, M. P. Finke, J. Li, D. A. Lappi, D. A. Simone, P. W. Mantyh, Transmission of chronic nociception by spinal neurons expressing the substance $\mathrm{P}$ receptor. Science 286, 1558-1561 (1999).

12. M. H. Ossipov, G. O. Dussor, F. Porreca, Central modulation of pain. J Clin Invest 120, 3779-3787 (2010).

13. F. Porreca, S. E. Burgess, L. R. Gardell, T. W. Vanderah, T. P. Malan, Jr., M. H. Ossipov, D. A. Lappi, J. Lai, Inhibition of neuropathic pain by selective ablation of brainstem medullary cells expressing the mu-opioid receptor. $J$ Neurosci 21, 5281-5288 (2001).

14. D. C. Brown, K. Agnello, Intrathecal substance P-saporin in the dog: efficacy in bone cancer pain. Anesthesiology 119, 1178-1185 (2013).

15. J. Arsenault, E. Ferrari, D. Niranjan, S. A. Cuijpers, C. Gu, Y. Vallis, J. O'Brien, B. Davletov, Stapling of the botulinum type A protease to growth factors and neuropeptides allows selective targeting of neuroendocrine cells. $J$ Neurochem 126, 223-233 (2013).

16. F. Darios, D. Niranjan, E. Ferrari, F. Zhang, M. Soloviev, A. Rummel, H. Bigalke, J. Suckling, Y. Ushkaryov, N. Naumenko, A. Shakirzyanova, R. Giniatullin, E. Maywood, M. Hastings, T. Binz, B. Davletov, SNARE tagging 
allows stepwise assembly of a multimodular medicinal toxin. Proc Natl Acad Sci U S A 107, 18197-18201 (2010).

17. M. Montal, Botulinum neurotoxin: a marvel of protein design. Annual review of biochemistry 79, 591-617 (2010).

18. E. Ferrari, E. S. Maywood, L. Restani, M. Caleo, M. Pirazzini, O. Rossetto, M. H. Hastings, D. Niranjan, G. Schiavo, B. Davletov, Re-Assembled Botulinum Neurotoxin Inhibits CNS Functions without Systemic Toxicity. Toxins (Basel) 3, 345-355 (2011).

19. R. Hepp, M. Perraut, S. Chasserot-Golaz, T. Galli, D. Aunis, K. Langley, N. J. Grant, Cultured glial cells express the SNAP-25 analogue SNAP-23. Glia 27, 181-187 (1999).

20. V. Schubert, D. Bouvier, A. Volterra, SNARE protein expression in synaptic terminals and astrocytes in the adult hippocampus: a comparative analysis. Glia 59, 1472-1488 (2011).

21. C. De Felipe, J. F. Herrero, J. A. O'Brien, J. A. Palmer, C. A. Doyle, A. J. Smith, J. M. Laird, C. Belmonte, F. Cervero, S. P. Hunt, Altered nociception, analgesia and aggression in mice lacking the receptor for substance P. Nature 392, 394-397 (1998).

22. A. S. Mangione, I. Obara, M. Maiaru, S. M. Geranton, C. Tassorelli, E. Ferrari, C. Leese, B. Davletov, S. P. Hunt, Nonparalytic botulinum molecules for the control of pain. Pain 157, 1045-1055 (2016).

23. J. F. Bernard, R. Dallel, P. Raboisson, L. Villanueva, D. Le Bars, Organization of the efferent projections from the spinal cervical enlargement to the parabrachial area and periaqueductal gray: a PHA-L study in the rat. $J$ Comp Neurol 353, 480-505 (1995).

24. K. Feil, H. Herbert, Topographic organization of spinal and trigeminal somatosensory pathways to the rat parabrachial and Kolliker-Fuse nuclei. J Comp Neurol 353, 506-528 (1995).

25. J. L. Brown, H. Liu, J. E. Maggio, S. R. Vigna, P. W. Mantyh, A. I. Basbaum, Morphological characterization of substance $\mathrm{P}$ receptor-immunoreactive neurons in the rat spinal cord and trigeminal nucleus caudalis. J Comp Neurol 356, 327-344 (1995).

26. S. P. Hunt, A. Pini, G. Evan, Induction of c-fos-like protein in spinal cord neurons following sensory stimulation. Nature 328, 632-634 (1987).

27. B. L. Kieffer, C. Gaveriaux-Ruff, Exploring the opioid system by gene knockout. Progress in neurobiology 66, 285-306 (2002).

28. T. Kemp, R. C. Spike, C. Watt, A. J. Todd, The mu-opioid receptor (MOR1) is mainly restricted to neurons that do not contain GABA or glycine in the superficial dorsal horn of the rat spinal cord. Neuroscience 75, 1231-1238 (1996).

29. A. J. Todd, Identifying functional populations among the interneurons in laminae I-III of the spinal dorsal horn. Mol Pain 13, 1744806917693003 (2017).

30. D. Wang, V. L. Tawfik, G. Corder, S. A. Low, A. Francois, A. I. Basbaum, G. Scherrer, Functional Divergence of Delta and $\mathrm{Mu}$ Opioid Receptor Organization in CNS Pain Circuits. Neuron 98, 90-108 e105 (2018).

31. C. W. Stevens, T. L. Yaksh, Spinal action of dermorphin, an extremely potent opioid peptide from frog skin. Brain Res 385, 300-304 (1986). 
32. H. Mizoguchi, G. Bagetta, T. Sakurada, S. Sakurada, Dermorphin tetrapeptide analogs as potent and long-lasting analgesics with pharmacological profiles distinct from morphine. Peptides 32, 421-427 (2011).

33. M. H. Rashid, M. Inoue, K. Toda, H. Ueda, Loss of peripheral morphine analgesia contributes to the reduced effectiveness of systemic morphine in neuropathic pain. J Pharmacol Exp Ther 309, 380-387 (2004).

34. H. Breivik, B. Collett, V. Ventafridda, R. Cohen, D. Gallacher, Survey of chronic pain in Europe: prevalence, impact on daily life, and treatment. Eur J Pain 10, 287-333 (2006).

35. A. J. Todd, Neuronal circuitry for pain processing in the dorsal horn. Nat Rev Neurosci 11, 823-836 (2010).

36. R. Baron, A. Binder, Fighting neuropathic pain with botulinum toxin A. The Lancet. Neurology 15, 534-535 (2016).

37. P. G. Foran, N. Mohammed, G. O. Lisk, S. Nagwaney, G. W. Lawrence, E. Johnson, L. Smith, K. R. Aoki, J. O. Dolly, Evaluation of the therapeutic usefulness of botulinum neurotoxin $B, C 1, E$, and F compared with the long lasting type A. Basis for distinct durations of inhibition of exocytosis in central neurons. J Biol Chem 278, 1363-1371 (2003).

38. J. E. Keller, E. A. Neale, The role of the synaptic protein snap-25 in the potency of botulinum neurotoxin type A. J Biol Chem 276, 13476-13482 (2001).

39. K. Paterson, S. Lolignier, J. N. Wood, S. B. McMahon, D. L. Bennett, Botulinum toxin-A treatment reduces human mechanical pain sensitivity and mechanotransduction. Ann Neurol 75, 591-596 (2014).

40. F. Pavone, S. Luvisetto, Botulinum neurotoxin for pain management: insights from animal models. Toxins (Basel) 2, 2890-2913 (2010).

41. P. P. Huang, I. Khan, M. S. Suhail, S. Malkmus, T. L. Yaksh, Spinal botulinum neurotoxin B: effects on afferent transmitter release and nociceptive processing. PLoS One 6, e19126 (2011).

42. N. Attal, D. C. de Andrade, F. Adam, D. Ranoux, M. J. Teixeira, R. Galhardoni, I. Raicher, N. Uceyler, C. Sommer, D. Bouhassira, Safety and efficacy of repeated injections of botulinum toxin $A$ in peripheral neuropathic pain (BOTNEP): a randomised, double-blind, placebo-controlled trial. The Lancet. Neurology 15, 555-565 (2016).

43. D. Ranoux, N. Attal, F. Morain, D. Bouhassira, Botulinum toxin type A induces direct analgesic effects in chronic neuropathic pain. Ann Neurol 64, 274-283 (2008).

44. J. L. Jackson, A. Kuriyama, Y. Hayashino, Botulinum toxin A for prophylactic treatment of migraine and tension headaches in adults: a meta-analysis. JAMA 307, 1736-1745 (2012).

45. R. Ramachandran, T. L. Yaksh, Therapeutic use of botulinum toxin in migraine: mechanisms of action. Br J Pharmacol 171, 4177-4192 (2014).

46. L. Negri, P. Melchiorri, R. Lattanzi, Pharmacology of amphibian opiate peptides. Peptides 21, 1639-1647 (2000).

47. G. Mustafa, E. M. Anderson, Y. Bokrand-Donatelli, J. K. Neubert, R. M. Caudle, Anti-nociceptive effect of a conjugate of substance $\mathrm{P}$ and light chain of botulinum neurotoxin type A. Pain 154, 2547-2553 (2013). 
48. R. Tomasoni, D. Repetto, R. Morini, C. Elia, F. Gardoni, M. Di Luca, E. Turco, P. Defilippi, M. Matteoli, SNAP-25 regulates spine formation through postsynaptic binding to p140Cap. Nat Commun 4, 2136 (2013).

49. P. Y. Cheng, A. Moriwaki, J. B. Wang, G. R. Uhl, V. M. Pickel, Ultrastructural localization of mu-opioid receptors in the superficial layers of the rat cervical spinal cord: extrasynaptic localization and proximity to Leu5enkephalin. Brain Res 731, 141-154 (1996).

50. M. Ninkovic, S. P. Hunt, J. R. Gleave, Localization of opiate and histamine H1-receptors in the primate sensory ganglia and spinal cord. Brain Res 241, 197-206 (1982).

51. C. Gauriau, J. F. Bernard, Pain pathways and parabrachial circuits in the rat. Exp Physiol 87, 251-258 (2002).

52. C. A. Campos, A. J. Bowen, C. W. Roman, R. D. Palmiter, Encoding of danger by parabrachial CGRP neurons. Nature 555, 617-622 (2018).

53. S. Han, M. T. Soleiman, M. E. Soden, L. S. Zweifel, R. D. Palmiter, Elucidating an Affective Pain Circuit that Creates a Threat Memory. Cell 162, 363-374 (2015).

54. M. M. Heinricher, I. Tavares, J. L. Leith, B. M. Lumb, Descending control of nociception: Specificity, recruitment and plasticity. Brain Res Rev 60, 214225 (2009).

55. G. Corder, V. L. Tawfik, D. Wang, E. I. Sypek, S. A. Low, J. R. Dickinson, C. Sotoudeh, J. D. Clark, B. A. Barres, C. J. Bohlen, G. Scherrer, Loss of mu opioid receptor signaling in nociceptors, but not microglia, abrogates morphine tolerance without disrupting analgesia. Nat Med 23, 164-173 (2017).

56. M. Ninkovic, S. P. Hunt, J. S. Kelly, Effect of dorsal rhizotomy on the autoradiographic distribution of opiate and neurotensin receptors and neurotensin-like immunoreactivity within the rat spinal cord. Brain Res 230, 111-119 (1981).

57. R. H. t. Kline, R. G. Wiley, Spinal mu-opioid receptor-expressing dorsal horn neurons: role in nociception and morphine antinociception. $J$ Neurosci 28, 904-913 (2008).

58. R. L. Pennock, M. S. Dicken, S. T. Hentges, Multiple inhibitory G-proteincoupled receptors resist acute desensitization in the presynaptic but not postsynaptic compartments of neurons. J Neurosci 32, 10192-10200 (2012).

59. S. M. Hayek, T. R. Deer, J. E. Pope, S. J. Panchal, V. B. Patel, Intrathecal therapy for cancer and non-cancer pain. Pain Physician 14, 219-248 (2011).

60. T. L. Yaksh, C. J. Fisher, T. M. Hockman, A. J. Wiese, Current and Future Issues in the Development of Spinal Agents for the Management of Pain. Curr Neuropharmacol 15, 232-259 (2017).

61. J. E. Pope, T. R. Deer, B. M. Bruel, S. Falowski, Clinical Uses of Intrathecal Therapy and Its Placement in the Pain Care Algorithm. Pain Pract, (2016).

62. R. E. Miller, A. M. Malfait, J. A. Block, Current status of nerve growth factor antibodies for the treatment of osteoarthritis pain. Clin Exp Rheumatol 35 Suppl 107, 85-87 (2017).

63. N. E. Lane, M. Corr, Osteoarthritis in 2016: Anti-NGF treatments for pain two steps forward, one step back? Nat Rev Rheumatol 13, 76-78 (2017). 
64. L. F. Chu, M. S. Angst, D. Clark, Opioid-induced hyperalgesia in humans: molecular mechanisms and clinical considerations. Clin J Pain 24, 479496 (2008).

65. E. Ferrari, M. Soloviev, D. Niranjan, J. Arsenault, C. Gu, Y. Vallis, J. O'Brien, B. Davletov, Assembly of protein building blocks using a short synthetic peptide. Bioconjug Chem 23, 479-484 (2012).

66. S. R. Chaplan, F. W. Bach, J. W. Pogrel, J. M. Chung, T. L. Yaksh, Quantitative assessment of tactile allodynia in the rat paw. J Neurosci Methods 53, 5563 (1994).

67. M. Maiaru, K. K. Tochiki, M. B. Cox, L. V. Annan, C. G. Bell, X. Feng, F. Hausch, S. M. Geranton, The stress regulator FKBP51 drives chronic pain by modulating spinal glucocorticoid signaling. Science translational medicine 8, 325ra319 (2016).

68. I. Decosterd, C. J. Woolf, Spared nerve injury: an animal model of persistent peripheral neuropathic pain. Pain 87, 149-158 (2000).

69. C. A. Fairbanks, Spinal delivery of analgesics in experimental models of pain and analgesia. Adv Drug Deliv Rev 55, 1007-1041 (2003).

70. C. Mills, D. Leblond, S. Joshi, C. Zhu, G. Hsieh, P. Jacobson, M. Meyer, M. Decker, Estimating efficacy and drug ED50's using von Frey thresholds: impact of weber's law and log transformation. J Pain 13, 519-523 (2012).

ACKNOWLEDGMENTS: We thank S.M. Géranton for the helpful discussion during the preparation of the manuscript. We would like to thank Dan Wheeler and Jo Mullen for comments on the manuscript. We also thank Kurt de Vos and Rebecca Bresnahan from the University of Sheffield for supplying the rat cortical neurons and Simon Beggs for instruction in image analysis. FUNDING: This work was supported by the Medical Research Council grant MR/K022539/1. AUTHOR CONTRIBUTIONS: MM, B.D and S.P.H designed the experiments. J.A, C.L. and B.D designed and synthesised the botulinum constructs. S.P.H, M.M. C.L and B.D wrote the manuscript. M.M. and M.C conducted the behavioural experiments. M.M., I. E.A. and A.S.M conducted the immunohistochemical experiments. M.M and S.P.H analysed the data. COMPETING INTERESTS: The authors declare that they have no competing interests.

Fig 1: SP-BOT administered intrathecally (i.t.) reduced the mechanical hypersensitivity that developed in long-term inflammatory and neuropathic pain states. A) Mechanical threshold assessed using von Frey filaments in naïve mice before (B1) and 1-7 days (D1 to D7) after i.t. injection of SP-BOT (100ng/3 $\mu \mathrm{l} n=4$ per 
group). (B) Time on rotarod apparatus after SP-BOT i.t. injection ( $n=4$ per group) (C) Von Frey filaments were used to measure mechanical hypersensitivity in mice injected with $5 \mu$ l of Complete Freund's Adjuvant (CFA) in the ankle joint and 3 days later injected with i.t. SP-BOT (100ng/3 $\mu$ l). Mice were tested at baseline and up to 21 days after CFA injection ( $n=5-6$ per group). (D) CFA (20 $\mu$ l) was also injected into the plantar surface of the hindpaw, and 4 days later mice received i.t. SP-BOT (100ng/3 $\mu \mathrm{l} ; \mathrm{n}=7$ per group). (E) SP-BOT was injected i.t. 5 days after spared nerve injury (SNI) and alleviated the neuropathic mechanical sensitivity that had developed ( $n=8$ per group). (F) NK1R knockout mice and their wild-type littermates received i.t. SP-BOT 5 days after SNI ( $n=8$ per group). Data show means \pm SEM (Standard Error of the Mean). (D: Day) ${ }^{*} P<0.05,{ }^{* *} P<0.01,{ }^{* * *} P<0.001$. Difference in sensitivity was assessed using repeated-measured two-way followed by one-way ANOVA. For complete statistical analyses, please refer to Supplementary Table 1 and for maximum possible effect (\%MPE) please refer to Supplementary Table 2.

Fig 2: SP-BOT was internalized by NK1R-positive neurons without toxicity. (A) Images of NK1R and cSNAP25 immunoreactivity in the superficial dorsal horn of mice $14 \mathrm{~d}$ after i.t. injection of SP-BOT. Green, cSNAP25; red, NK1R. Scale bar 100 $\mu \mathrm{m}$. (B) Images of selective targeting of NK1R expressing neurons in the superficial dorsal horn 96h (top) or 14d (bottom) after i.t. injection of SP-BOT. Green, cSNAP25; red, NK1R. Scale bar top row $20 \mu \mathrm{m}$, bottom rows $10 \mu \mathrm{m}$. (C) Schematic illustration and images of the lateral parabrachial area ( $\mathrm{LPb})$ of mice 25 days after the i.t. injection of SP-BOT or saline. cSNAP25 in spino-parabrachial axons in green. Scale bar $80 \mu \mathrm{m}$. DRG: dorsal root ganglia (D) Bar graph illustrating the number of cFos- 
immunostained nuclei in the PB from both saline and SP-BOT injected mice. Mice received i.t. SP-BOT and 3 days later they were injected with CFA into the plantar surface of the hind paw. Tissue was taken $6 \mathrm{~h}$ later. Values reported are the mean number of c-Fos+ nuclei ( \pm SEM) normalized to the mean of c-Fos ${ }^{+}$nuclei in naïve control mice ( $n=4$ per group). (E) Quantification of NK1R fluorescence intensity in the contralateral superficial dorsal horn of mice $18 \mathrm{~d}$ after intraplantar CFA injection and 14 days after i.t. injection of SP-BOT or saline. All data were normalized to laminae $\mathrm{I} / \mathrm{II}$ saline-treated mice ( $\mathrm{n}=4$ per group). ${ }^{*} \mathrm{P}<0.05$ The comparison of three groups was determined using one-way ANOVA.

Fig 3: Derm-BOT reduced the mechanical hypersensitivity in inflammatory and neuropathic pain models in mice. (A) Mechanical threshold assessed using von Frey filaments in naïve mice before (B1) and after (Day1 to Day7 (D1 - D7)) i.t. injection of Derm-BOT (100ng/3 $\mu \mathrm{l} n=4$ per group). (B) Mechanical threshold was measured in mice before and after CFA injection $(5 \mu l)$ in the ankle joint. 4 days later mice were injected i.t. with Derm-BOT $(100 \mathrm{ng} / 3 \mu \mathrm{l})$. Mice were tested at baseline and up to 14 days after CFA injection ( $n=5$ per group). (C) CFA (20 $\mu$ l) was injected into the plantar surface of the hind paw and 4 days later mice received i.t. Derm-BOT (100ng/3 $\mu \mathrm{l} ; \mathrm{n}=8$ per group). (D) Mechanical threshold measured using von Frey filaments in mice injected with CFA $(5 \mu \mathrm{l})$ in the ankle joint and 3 days later injected with i.t. SP-BOT $(100 \mathrm{ng} / 3 \mu \mathrm{l})$. 2 weeks later mice injected with SP-BOT were reinjected with i.t. Derm-BOT ( $n=4$ per group). (E) Derm-BOT was injected i.t. in mice 5 days after SNI surgery ( $n=9$ per group). Data show means \pm SEM. ${ }^{*} \mathrm{P}<0.05,{ }^{* *} \mathrm{P}<$ 
$0.01, * * * \mathrm{p} \leq 0.001$. Difference in sensitivity was assessed using repeated-measured two-way followed by one-way ANOVA.

Fig 4: Derm-BOT was internalized by MOR expressing neurons. (A) Images of CSNAP25 and MOR immunoreactivity in the superficial dorsal horn of mice 14d after injection of i.t. Derm-BOT. Green, cSNAP25; red, MOR. Scale bar $100 \mu \mathrm{m}$. (B) Images of selective targeting of cSNAP to MOR expressing neurons in the superficial dorsal horn $96 \mathrm{~h}$ (top and bottom row) or 14d after i.t. injection of Derm-BOT. Green, cSNAP25; red, MOR. Scale bar top row $20 \mu \mathrm{m}$, middle and bottom row $10 \mu \mathrm{m}$.

Fig 5: Derm-BOT preclude the effect of morphine and retains efficacy in NK1R knockout mice. (A) Mechanical threshold using von Frey filaments in mice injected i.t. with Derm-BOT 5 days after SNI surgery. 29 days later mice were injected with i.t. morphine (5nM, $n=9$ per group). (B) Mechanical threshold measured using von Frey filaments in NK1R knockout mice before and after SNI surgery. 5 days after surgery mice were injected with i.t. SP-BOT and 2 weeks later were injected with i.t. DermBOT ( $n=8$ per group). Data show means \pm SEM. ${ }^{*}$ or ${ }^{\#} \mathrm{P}<0.05,{ }^{* *} \mathrm{P}<0.01, * * *$ or ${ }^{\# \# \#} \mathrm{P}$ $\leq 0.001$. Difference in sensitivity was assessed using repeated-measured two-way followed by one-way ANOVA. 
Figure 1

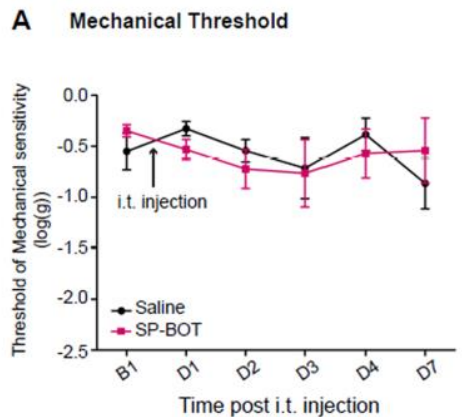

B

Locomotor activity

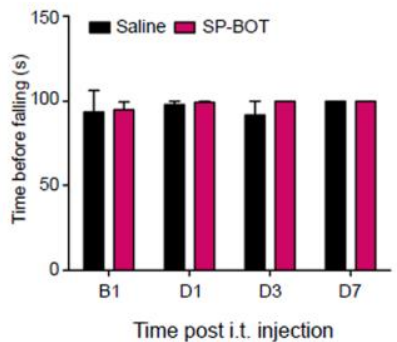

D Mechanical Threshold

E Mechanical Threshold
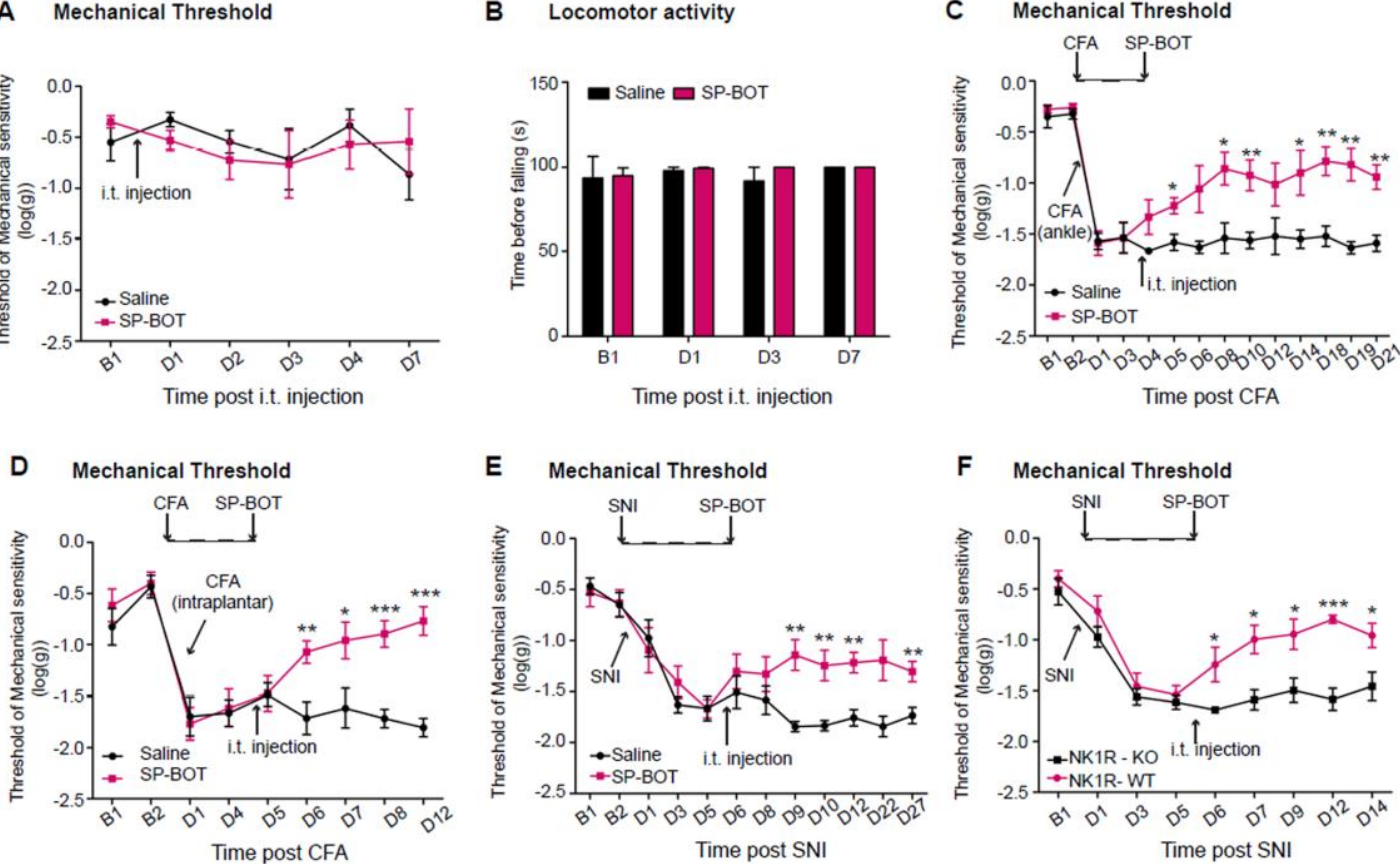
Figure 2
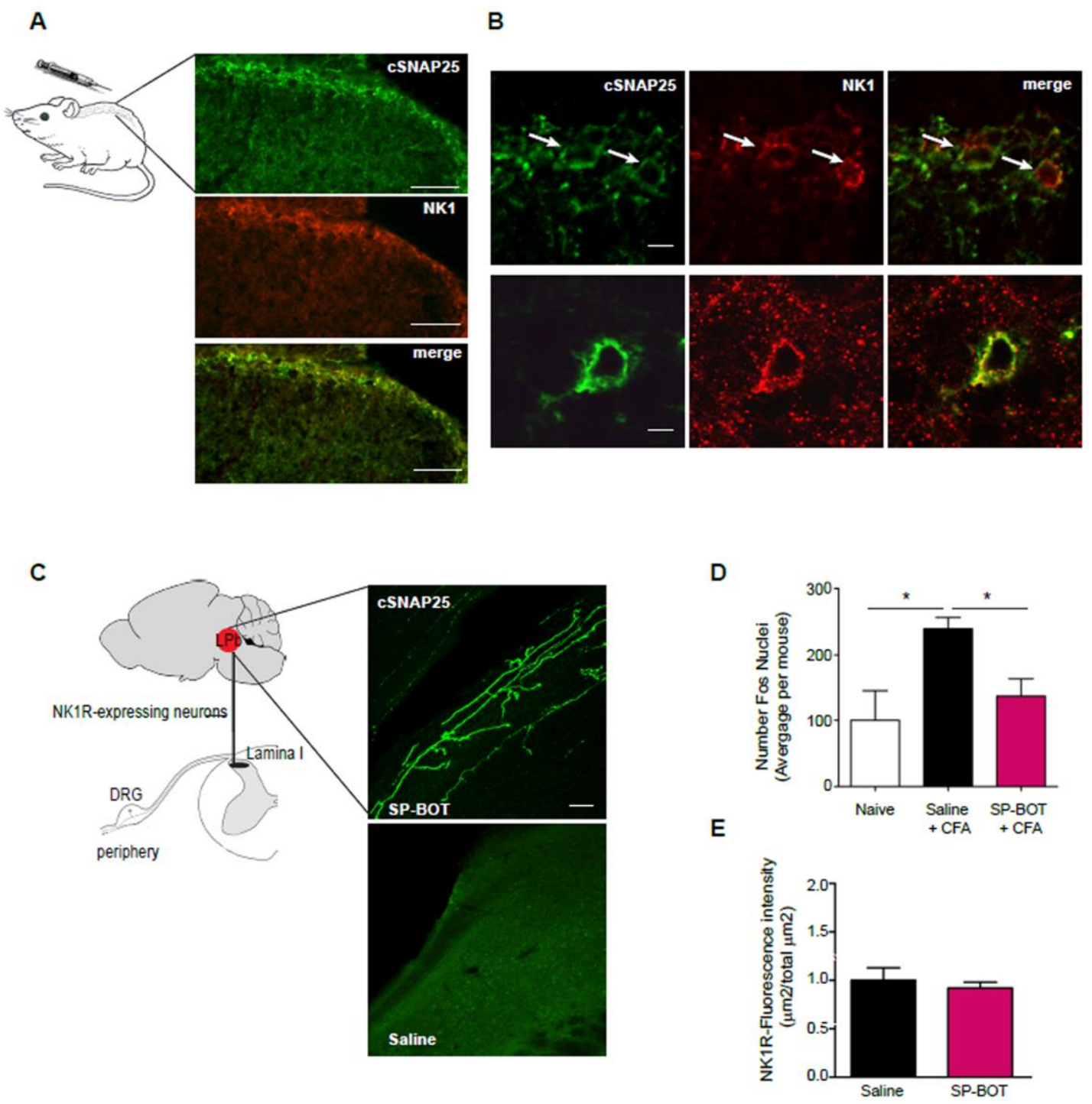


\section{Figure 3}

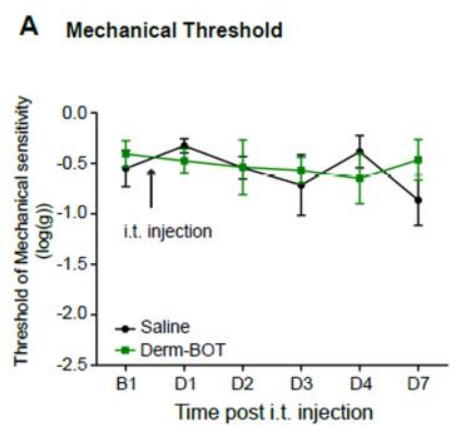

B Mechanical Threshold
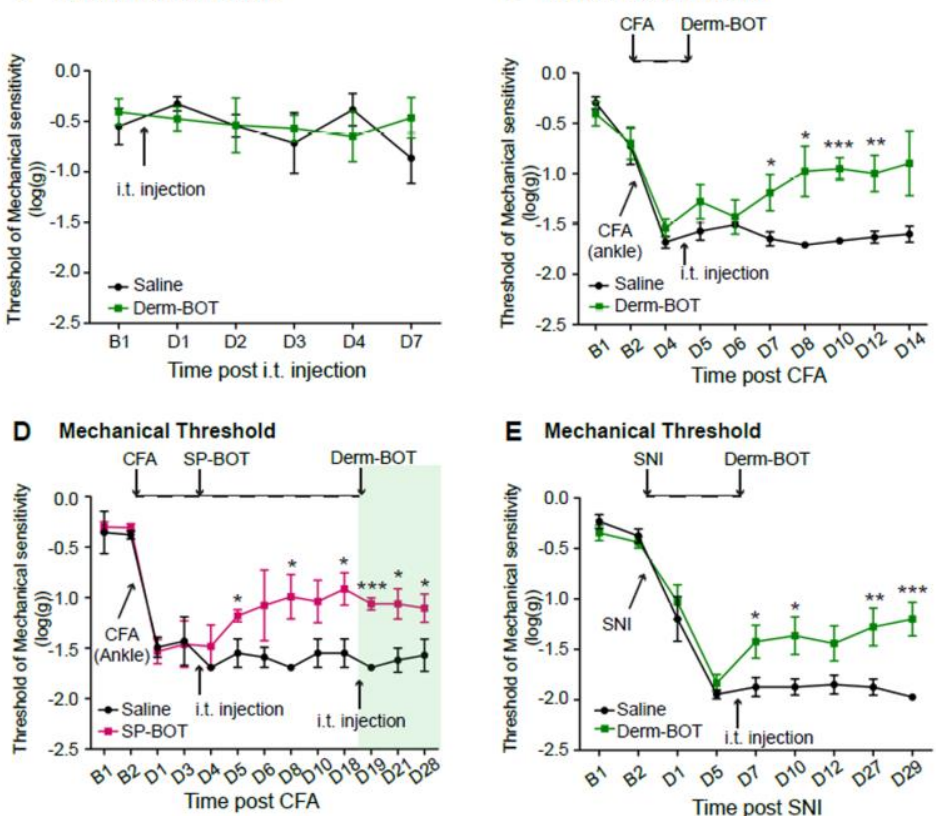

E Mechanical Threshold
C Mechanical Threshold
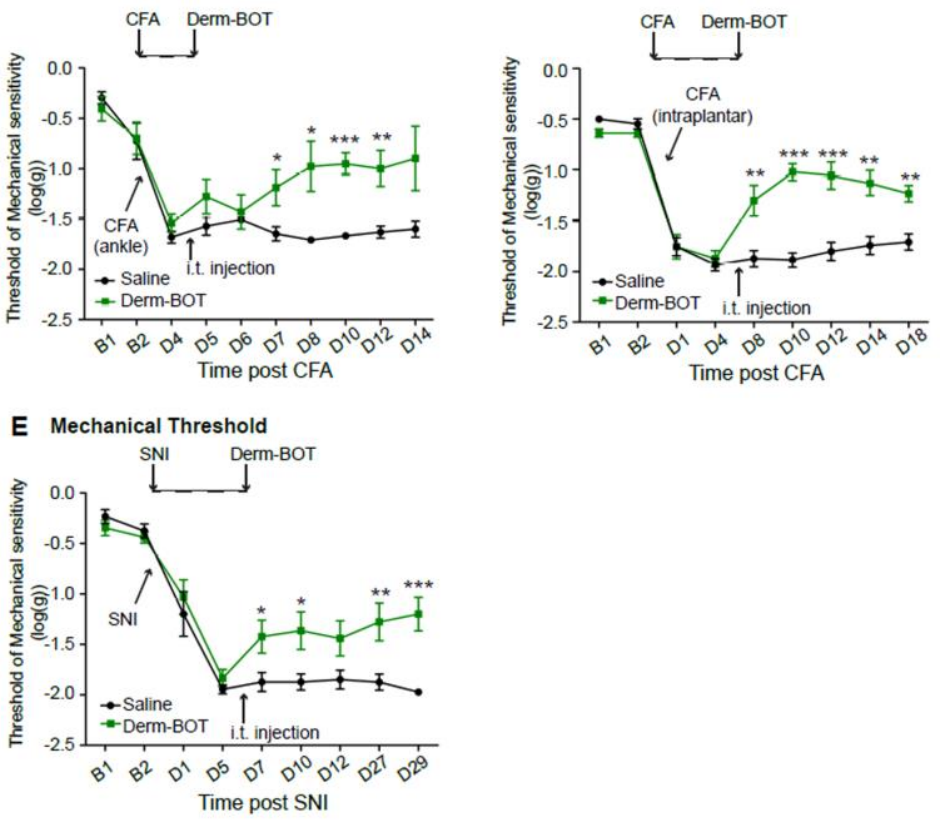

\section{Figure 4}

A

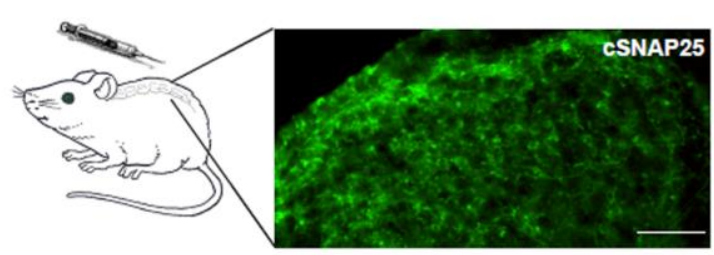

T MOR
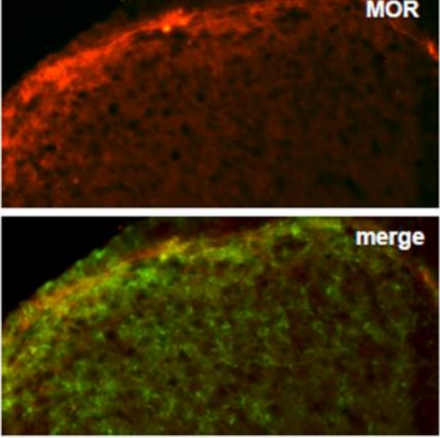

B

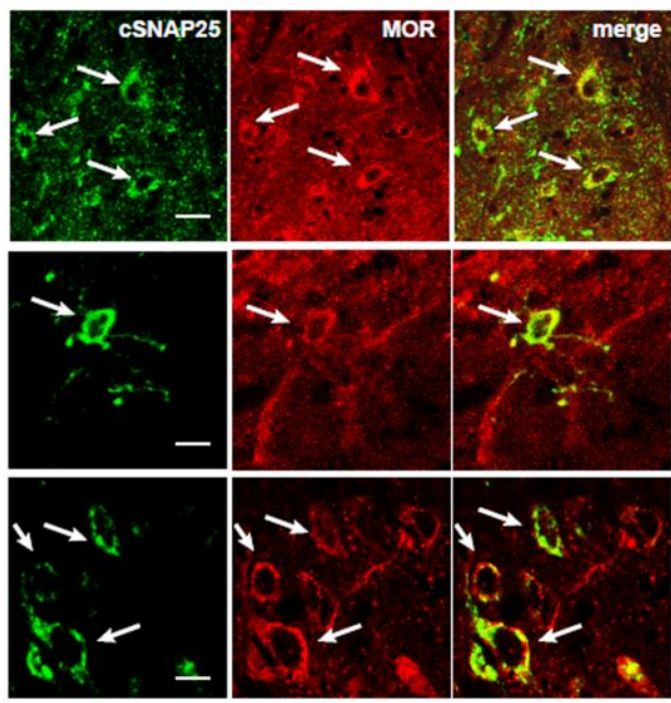




\section{Figure 5}

\section{A Mechanical Threshold}

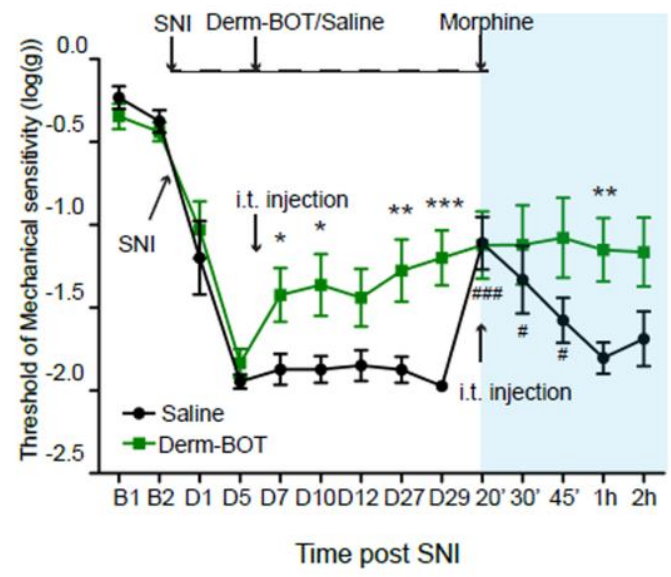

B Mechanical Threshold NK1R $/$ - mice

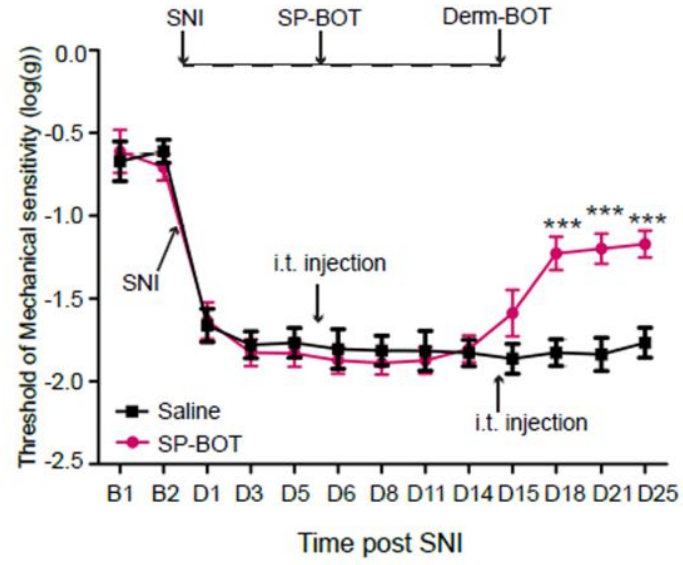

